\title{
Modelling storm response on gravel beaches using XBeach-G
}

\author{
Masselink, Gerd
}

http://hdl.handle.net/10026.1/3172

10.1680/maen.14.00020

Proceedings of the ICE - Maritime Engineering

Thomas Telford Ltd.

All content in PEARL is protected by copyright law. Author manuscripts are made available in accordance with publisher policies. Please cite only the published version using the details provided on the item record or document. In the absence of an open licence (e.g. Creative Commons), permissions for further reuse of content should be sought from the publisher or author. 


\title{
MODELLING STORM RESPONSE ON GRAVEL BEACHES USING XBEACH-G
}

Gerd Masselink (MSc, PhD), Professor in Coastal Geomorphology at Plymouth University (UK)

Robert McCall (MSc), Researcher/Consultant at Deltares, Delft (The Netherlands)

Tim Poate (MSc, PhD), Post-Doctoral Research Fellow at Plymouth University (UK)

Pieter van Geer (MSc), Researcher/Advisor at Deltares, Delft (The Netherlands)

\section{Submitted to Proceedings of the ICE - Maritime Engineering}

\begin{abstract}
Despite the clear societal importance of gravel beaches and barriers in protecting coastal areas from flooding, there are currently no reliable numerical models for predicting the morphological response of gravel beaches to storm events. In this paper we synthesises the results of a research project (NUPSIG) aimed at reducing this shortfall through an integrated research approach, involving field experimentation, comprehensive beach monitoring and innovative numerical modelling. In particular, we introduce a storm impact model for gravel beaches and barriers developed during the project (XBeach-G), present a brief validation of the model using field data and describe a user-friendly graphical user interface for the model. Finally, we apply the model in two case studies to demonstrate the use of the model in decision-making processes related to coastal flooding and beach maintenance.
\end{abstract}

\section{Introduction}

Gravel barriers and beaches extend along more than 1,000 $\mathrm{km}$ of the coastline of England and Wales and represent sustainable coastal defences that can protect low-lying back-barrier regions from flooding during storm events. They are also widespread along other high-latitude coasts (e.g., Ireland, Canada), high-relief coasts (e.g., Japan, New Zealand) and in the Mediterranean (e.g., Cote d'Azur). Their societal role is widely acknowledged and coastal engineering structures (seawalls and groins) and management techniques (recharge, recycling and reshaping) are extensively used, at significant cost, to maintain and enhance their protective ability (e.g., Moses and Williams, 2009). Gravel is even used to create beaches, for example, in Lake Montana on a small scale (Lorang, 1991) to produce sustainable coastal protection structures.

Jennings and Schulmeister (2002) define three types of gravel beaches: (1) 'pure' gravel beaches consisting gravel-size material $\left(D_{50}=0.002-0.064 \mathrm{~m}\right)$ across the entire intertidal region; (2) 'composite' gravel beaches comprising of a pure gravel high tide beach fronted by a sandy low tide terrace; and (3) 'mixed' gravel beaches consisting of a mixture of sand and gravel sediment. Field data from all three gravel beaches types 
are represented in this paper, but the numerical model discussed here has specifically been developed to predict the morphodynamic behaviour for the pure gravel beach type (e.g., profile response); however, the hydrodynamics predicted by the model (e.g., wave runup) are also applicable to the mixed and composite gravel beach types.

Coastal erosion is widespread along gravel beaches in the UK (e.g., Chadwick et al., 2005; Pye and Blott, 2006, 2009) and at other locations (e.g., Komar, 2010), with erosion rates expected to increase as a result of sea-level rise and possibly enhanced storminess due to climate change. Gravel beach erosion can occur along the entire beach frontage as a result of barrier roll-over, or can be more localised where erosion along one end of the beach is accompanied by accretion at the opposite end (i.e., beach rotation). The need to understand and model morphodynamic processes on gravel beaches has been recognised by the Department of Environment, Food and Rural Affairs (DEFRA), which has commissioned a number of research projects concerning gravel barriers and beaches over the past few years (see projects FD1901, FD1923, FD1924 and FD1304 on http://randd.defra.gov.uk/). The key conclusion of the most recent project Understanding Barrier Beaches (FD1924) is that regular breaching and extensive storm damage has occurred at many gravel barrier sites in the UK and that limited scientific guidance is currently available to provide beach managers with operational management tools to predict the response of these beaches to storm conditions.

Two features in particular distinguish gravel beaches from their sandy counterparts: steeper beach gradient and much greater sediment permeability. As a result of the steeper beach slope, waves tend to break over a shorter distance and more violently than on a sandy beach, and can result in higher wave runup than on sandy beaches (Polidoro et al., 2013; Poate et al, in prep.). Most of the sediment transport takes place in the swash zone, rather than the surf zone, giving rise to the development of swash morphology (berm, cusps, step; Poate et al., 2013), instead of nearshore bars, troughs and rip channels. Due to the greater permeability of gravel compared to sand, in/exfiltration effects are expected to be more significant on gravel beaches (Kirk, 1975; She et al., 2007). Specifically, swash infiltration losses will be greater (Austin and Masselink, 2006), creating asymmetry in the swash transport potential, and reducing overwash volumes.

Despite our qualitative understanding of gravel barrier dynamics, we are not able to confidently predict the morphological response of gravel beaches to changing wave and water-level conditions. Even our ability to make predictions of the type of gravel beach response is limited. Two parametric models are currently in use for predicting storm impacts on gravel barriers (Obhrai et al., 2008). The Powell (1990) model is based on the concept of an equilibrium beach profile, while the approach of Bradbury (2002) uses a barrier inertia parameter, reflecting the balance between wave forcing and barrier resistance, to assess the occurrence of overtopping, overwashing and breaching (cf. Bradbury et al., 2005). These models are useful in their own right, but cannot be applied to predict the temporal morphological development, because actual cross-shore 
sediment transport rates are not considered. Numerical models developed for sandy beaches may be used to predict the morphological response of gravel beaches, but fundamental differences between sandy and gravel beach dynamics (e.g., López de San Román-Blanco, 2006; Buscombe and Masselink, 2006) preclude their application without significant modifications. It is therefore a necessary conclusion that there is currently no reliable numerical model available for predicting the morphological response of gravel beaches to changing wave/tide conditions over the short- to medium-term time scale (minutes to weeks).

This paper synthesises the result of a research project specifically aimed to develop a capability to predict the response of gravel beaches to extreme wave and water-level conditions through an integrated research approach, involving field experimentation, comprehensive beach monitoring and innovative numerical modelling (NUPSIG project: New Understanding and Prediction of Storm Impacts on Gravel beaches). Rather than developing a new model from first principles, the approach adopted here is to use an existing model that has been applied successfully to sandy beaches and modify the model for use on gravel beaches using field data. The model used as a starting point is the XBeach model (Roelvink et al., 2009), which has been specifically developed to predict hurricane impacts on sandy barriers. The modified model is referred to as XBeach-G (as in XBeach-Gravel) and to enable wide use of this model by coastal managers and coastal engineers, a Graphical User Interface (GUI) was developed to facilitate setting up the model, and inspecting and exporting the model output.

The objectives of this paper are to describe the basic equations underpinning the XBeach-G model, present a brief validation of the model using field data, introduce the GUI and illustrate input and export options, use two case studies to demonstrate the use of the model and outline the model capabilities and limitations.

\section{XBeach-G model description}

The model used in this paper, XBeach-G (McCall et al., 2014; McCall et al., in prep), constitutes a 1D (cross-shore transect) extension of the XBeach storm-impact model (Roelvink et al., 2009) for gravel beaches through the application of: (1) a non-hydrostatic pressure correction term that allows wave-by-wave modelling of the surface elevation and depth-averaged flow; (2) a groundwater model that allows infiltration and exfiltration through the permeable gravel bed to be simulated; and (3) sediment transport relations that account for gravel bed load transport. The following sections address the main equations of the XBeach-G model; a full description of the hydrodynamic and morphodynamic equations, is provided by McCall et al. (2014) and McCall et al. (in prep), respectively.

\subsection{Equations for surface water including short waves}


XBeach-G uses a depth-averaged, non-hydrostatic extension to the standard XBeach model (Smit et al., 2010) that allows XBeach-G to solve not only long (infragravity) waves, but also wave-by-wave flow and surface elevation variations due to short waves in intermediate and shallow water depths (cf., SWASH model Zijlema et al. (2011) and Smit et al. (2013)), which are of particular importance on steep, reflective gravel beaches. Depth-averaged flow due to waves and currents are computed in XBeach-G using the nonlinear shallow water equations, including a non-hydrostatic pressure term and a source term for exchange with the groundwater:

$$
\begin{gathered}
\frac{\partial \zeta}{\partial t}+\frac{\partial h u}{\partial x}+S=0 \\
\frac{\partial u}{\partial t}+u \frac{\partial u}{\partial x}-v_{h} \frac{\partial^{2} u}{\partial x^{2}}=-\frac{1}{\rho} \frac{\partial(\bar{q}+\rho g \zeta)}{\partial x}-c_{f} \frac{u|u|}{h}
\end{gathered}
$$

where $x$ and $t$ are the horizontal spatial and temporal coordinates respectively, $\zeta$ is the free surface elevation above an arbitrary horizontal plane, $u$ is the depth-averaged cross-shore velocity, $h=\zeta-\xi$ is the total water depth, $\xi$ is the elevation of the bed above an arbitrary horizontal plane, $s$ is the surface watergroundwater exchange flux, $v_{H}$ is the horizontal viscosity, $\rho$ is the density of water, $\bar{q}$ is the depth-averaged dynamic pressure normalized by the density, $g$ is the gravitational constant and $c_{f}$ is the bed friction factor (computed using the Chézy equation for turbulent flow, assuming a roughness height of $3 D_{90}$ ).

\subsection{Equations for groundwater}

To correctly account for upper swash infiltration losses and exfiltration effects on lower swash hydrodynamics on gravel beaches, XBeach-G computes groundwater dynamics and the exchange between groundwater and surface water using a groundwater model (McCall et al., 2012). Horizontal groundwater flow in in the aquifer is computed assuming incompressible flow and the Law of Darcy (1856):

$$
\begin{gathered}
\frac{\partial h_{g w} u_{g w}}{\partial x}+w_{g w, s}=0 \\
u_{g w}=-K \frac{\partial \bar{H}}{\partial x}
\end{gathered}
$$

where $u_{g w}$ is the depth-averaged horizontal groundwater velocity, $h_{g w}$ is the height of the groundwater surface above the bottom of the aquifer, $w_{g w, s}$ is the vertical groundwater velocity at the groundwater surface, which includes the surface water-groundwater exchange flux $(s), \kappa$ is the hydraulic conductivity of the aquifer and $\bar{H}$ is the depth-averaged hydraulic head. Since Darcy's Law is only strictly valid for laminar flow, the model approximates turbulent groundwater flow conditions using a modification of the laminar hydraulic conductivity similar to Halford (2000): 


$$
K=\left\{\begin{array}{cc}
K_{\text {lam }} \sqrt{\frac{\operatorname{Re}_{\text {crit }}}{\operatorname{Re}}} & \operatorname{Re}>\operatorname{Re}_{\text {crit }} \\
K_{\text {lam }} & \operatorname{Re} \leq \operatorname{Re}_{\text {crit }}
\end{array}\right.
$$

where $\kappa_{\text {lam }}$ is the laminar hydraulic conductivity, Re is the current Reynolds number of the interstitial flow and $\mathrm{Re}_{\text {crit }}$ is the critical Reynolds number for the start of turbulent flow. Thus, for turbulent interstitial flow, the hydraulic conductivity $K$ decreases as the flow becomes more turbulent.

\subsection{Equations for sediment transport and morphology}

The dominant modes of sediment transport on gravel beaches are assumed to be bed load and sheet flow transport. The total gravel sediment transport is computed using a modification of the Meyer-Peter and Müller (1948) equation for bed load transport derived by Nielsen (2002):

$$
q_{s}=12(\theta-0.05) \sqrt{\theta} \sqrt{\left(\frac{\rho_{s}-\rho}{\rho}\right) g D_{50}^{3}}
$$

where $q_{s}$ is the volumetric sediment transport rate, $\theta$ is the Shields parameter, $\rho_{s}$ is the density of the sediment and $D_{50}$ is the median grain diameter. Following Fredsøe and Deigaard (1992), the Shields parameter is adjusted for bed slope effects:

$$
\theta=\frac{u_{*}^{2}}{\left(\frac{\rho_{s}-\rho}{\rho}\right) g D_{50}} \cos (\beta)\left(1 \pm \frac{\tan (\beta)}{\tan (\phi)}\right)
$$

where $u_{*}$ is the friction velocity, $\beta$ is the bed angle and $\phi$ is the angle of repose of the sediment.

To account for boundary layer expansion and contraction in the swash, pressure gradient effects, and the presence of turbulent fronts, the friction velocity is computed using the approximation of Nielsen (2002):

$$
u_{*}=\sqrt{\frac{f_{s}}{2}}\left(\cos (\varphi) u+\frac{T_{m-1,0}}{2 \pi} \sin (\varphi) \frac{\partial u}{\partial t}\right)
$$

where $f_{s}$ is a user-defined sediment friction factor in the order of $0.01, T_{m-1,0}$ is the offshore spectral period based on the first negative moment of the energy spectrum and $\varphi$ is a user-defined phase lag angle in the order of $30^{\circ}$.

Bed level changes are computed due to gradients in sediment transport:

$$
\frac{\partial \xi}{\partial t}+\frac{1}{1-n} \frac{\partial q_{s}}{\partial x}=0
$$

where $\xi$ is the elevation of the bed above an arbitrary horizontal plane. 
Finally, slope collapse and slumping is approximated by avalanching sediment downslope when the bed slope exceeds the angle of repose:

$$
\begin{aligned}
& \left|\frac{\partial \xi}{\partial x}\right|>\phi \quad \text { slumping } \\
& \left|\frac{\partial \xi}{\partial x}\right| \leq \phi \quad \text { no slumping }
\end{aligned}
$$

\section{Validation of XBeach-G}

Extensive validation of XBeach-G was conducted using field and laboratory data. Specific aspects of the validation include the transformation of waves through the narrow surf zone and lower swash zone, wave runup statistics, interactions between the swash flow and the beach groundwater table, and the beach morphological response in the swash, overtopping and overwash regimes. Extensive validation of the model has been presented in McCall et al. (2012, 2013, 2014, in prep) and Poate et al. (in prep); here, some of the key validation outputs are presented, focusing on the ability of the model to predict vertical runup, the occurrence of overwash and morphological response.

\subsection{Wave runup}

Storm response on gravel barriers primarily depends on the vertical wave runup in relation to the elevation of the barrier crest; therefore, a numerical model for predicting storm impacts on gravel beach must be able to confidently predict runup characteristics. Data on wave run-up levels were collected from a wide range of sources, including a cross-shore array of bed-level sensors deployed during a large-scale gravel barrier experiment in the Delta Flume (BARDEX experiment; Williams et al., 2012) and on a gravel beach in south Cornwall (Loe Bar; Poate et al., 2013), and pixel time stacks derived from video data during the field experiments carried out over the years on a number of gravel sites in the UK (Chesil, Hayling, Seascale, Slapton Sands, Westward Ho!; refer to McCall et al. (2014) for detailed description of these field experiments).

To compare predicted and measured run-up levels, XBeach models were set up for measurement series of the BARDEX experiment, as well as wave events at six gravel beaches along the UK coast (cf. Poate et al., in prep). Each simulation was run for the duration of maximum tide levels and contiguous camera or bedlevel sensor data, which was generally in the order of $0.5-1$ hours. Run-up exceedence levels $\left(R_{2 \%}, R_{5 \%}, R_{10 \%}\right.$ and $\left.R_{20 \%}\right)$ were computed from 15-20 minute sections of observed and modelled shoreline time series. To investigate the sensitivity of the modelled run-up levels to the selection of random wave components at the model boundary, each XBeach simulation was run ten times using a new random wave time series of the imposed offshore wave spectrum. 
Measured and modelled run-up levels at all sites are shown in Figure 1. Vertical error bars in the figure represent variations in the modelled run-up levels due to variations in the random wave time series applied at the model boundary. Horizontal error bars represent the variation in measured run-up data across multiple cross-shore profiles. The figure shows very good correspondence and little scatter (low scatter index; SCI) between measured and modelled run-up levels for all exceedence probabilities and at all gravel beaches. Importantly, the model shows practically no systematic relative bias (defined as the absolute bias, normalised by the measured run-up; $b_{\text {rel }}$ ) in the computation of the extreme run-up levels. There is a suggestion that there is more bias in the Chesil beach data, but these data are at the high energy end of field observations with vertical runup up to $12 \mathrm{~m}$ where any bias is more apparent when the data are plotted on a linear scale. Variations in modelled and measured run-up levels due to variations in the imposed wave time series and cross-shore camera pixel stacks are in the order of $1 \mathrm{~m}(20 \%)$ for run-up levels over $5 \mathrm{~m}$.
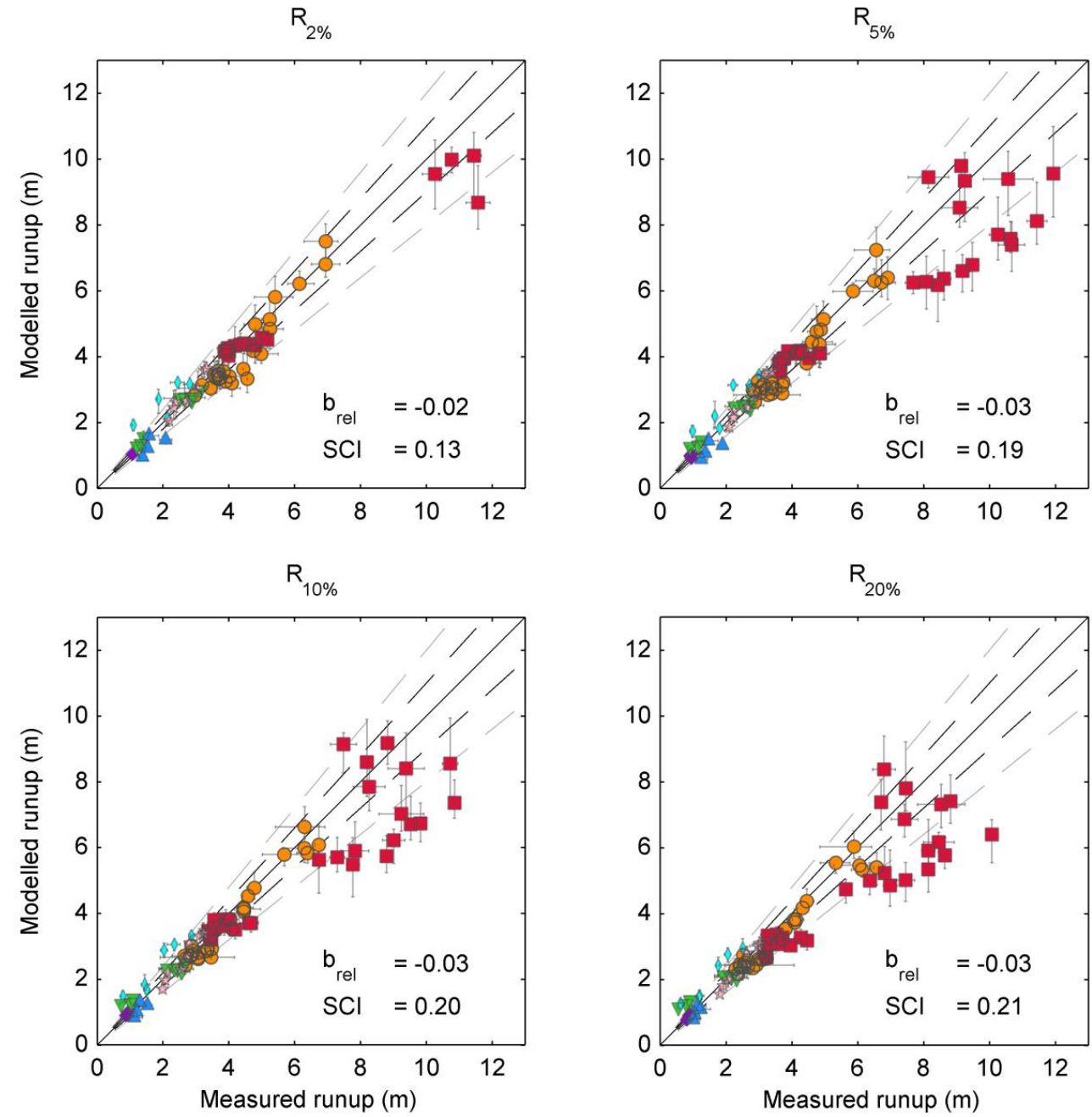

Figure 1 - Comparison of measured (horizontal axis) and modelled (vertical axis) runup heights (vertical runup relative to Still Water Level) at Chesil Beach (red squares; from pixel stacks), Loe Bar (orange circles; from bed-level sensors), Seascale (blue upward triangles; from pixel stacks), Slapton Sands (green downward triangles; from pixel stacks), Westward Ho! (cyan thin diamonds; from pixel stacks), Hayling Island (pink pentagons; from pixel stacks) and the BARDEX-experiment (violet diamonds; from bed-level sensors). The solid black line indicates a perfect 1:1 relationship, and the dashed black and grey lines indicate a 10\% and $20 \%$ deviation from the perfect relationship, respectively. $R_{2 \%}, R_{5 \%}, R_{10 \%}$ and $R_{20 \%}$ refers to $2 \%, 5 \%, 10 \%$ and $20 \%$ exceedance runup height, respectively. Adapted from McCall et al. (2014) and Poate et al. (in prep.). 
The Barrier Inertia Model (BIM; Bradbury, 2002) relates the probability of overwash on gravel beaches to the wave steepness of the incident waves $S_{w}$, and the dimensionless barrier inertia parameter $B I$, defined as:

$$
\begin{aligned}
& S_{w}=\frac{H_{s}}{L_{m}} \\
& B I=\frac{R_{c} A}{H_{s}^{3}}
\end{aligned}
$$

where $H_{s}$ is the significant wave height measured at 6-8 m water depth, $L_{m}$ is the deep water wave length computed using the mean wave period, $R_{c}$ is the freeboard, or height of the barrier crest above still water level, and $A$ is the cross sectional area of the barrier above the still water level. From analysis of laboratory and field data, Bradbury (2000) found barrier overwash is unlikely to occur when:

$$
B I>0.0006 S_{w}^{-2.54}
$$

Although the BIM is used in many locations in the UK, the data used to derive the threshold overwash relation are specific to the site and conditions where they were measured (Hurst Spit in the south of England). The model may therefore not be valid for other sections of the coast of the UK.

A series of 22 documented storm impacts on gravel barriers and 3 BARDEX physical model experiments (Williams et al., 2012) have been hindcast in order to validate the XBeach model approach (refer to McCall et al. (2014) for detailed description of these cases). In these hindcast simulations, the barrier geometry is parameterised using documented topographic and bathymetric data to estimate the toe depth, beach slope, seabed slope, crest height and barrier width, and a combination of observations and estimates is used to parameterise the hydraulic conductivity of the gravel barriers. The hindcast models are forced using documented maximum wave conditions and surge levels where available, and estimates combined with sensitivity bands where accurate data are not available. The model was run without updating the barrier morphology to only model the hydrodynamics, and the key model output that indicates the occurrence and extent of overwash is the water discharge across the barrier crest $Q_{\text {crest }}$. Extensive XBeach simulations using idealised barrier morphology and a range of forcing conditions, supported by engineering guidelines (Simm, 1991), suggests that $Q_{\text {crest }}=20 \mathrm{l} \mathrm{m}^{-1} \mathrm{~s}^{-1}$ can be used to separate non-overwash and overwash conditions (McCall et al., 2013).

The documented barrier storm response of the 25 hindcast events are categorised, based on the observed profile change and the amount of back-barrier flooding, into four levels of response: (1) rollback and severe overwash; (2) overwash damage and crest lowering; (3) overtopping and crest build-up; and (4) scour with 
no change to crest. The simulated overtopping discharges in the hindcast simulations are plotted in Figure 2 according to the location of the storm event in BIM parameter space and according to the classification of the barrier storm response (refer to figure caption for hindcast event codes):
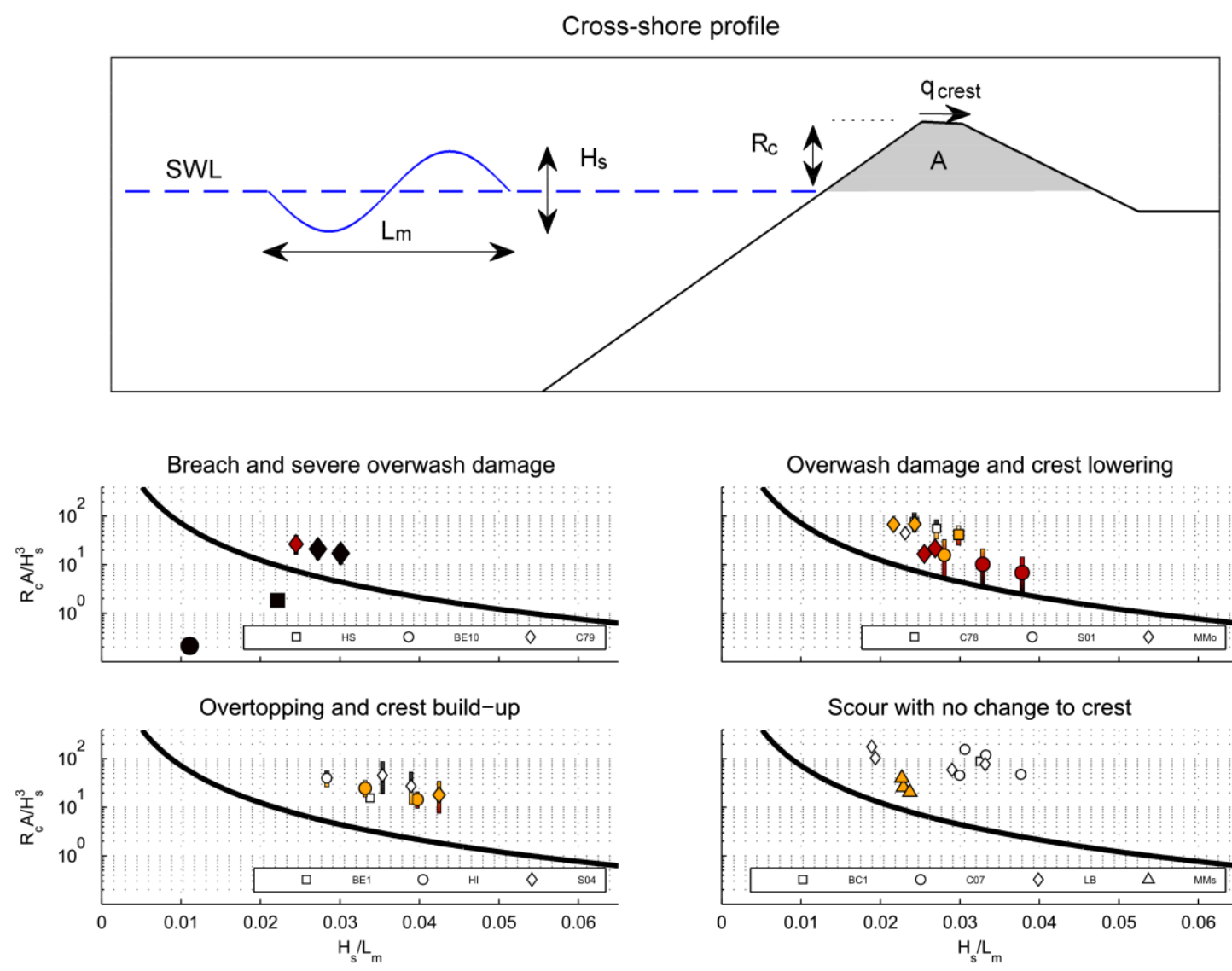

$\square \mathrm{q}_{\text {crest }}<2 \mathrm{ss}^{-1} \mathrm{~m}^{-1} \square \mathrm{q}_{\text {crest }}<201 \mathrm{~s}^{-1} \mathrm{~m}^{-1} \square \mathrm{q}_{\text {crest }}>201 \mathrm{~s}^{-1} \mathrm{~m}^{-1} \square \mathrm{q}_{\text {crest }}>100 \mathrm{ls} \mathrm{m}^{-1} \mathrm{~m}^{-1}$

Figure 2 - Simulated overtopping discharges across the barrier crest $\left(\mathrm{Q}_{\mathrm{crest}}\right)$ for hindcast tests. The top panel shows definition sketch of the Barrier Inertia Model (BIM); the lower panels compares the performance of the BIM (Eq. 14) and XBeach-G with observations. The black curve in the lower panels represents the; according to the BIM, overwash is unlikely to occur in the parameter space above the black curve. Marker colours relate to the simulated overtopping volumes across the barrier crest $\mathrm{Q}_{\mathrm{crest}}$ in XBeach-G. A total of 25 cases have been hindcasted: HS = Hurst Spit 1989; BE10 = BARDEX E10; C79 = Chesil Beach 1979; C78 = Chesil Beach 1978; S01 = Slapton sands 2001; MMo = Medmerry 1994-2000; HI = Hayling island 2005; S04 = Slapton Sands 2004; BC1 = BARDEX C1; C07 = Chesil Beach 2007-2010; LB = Loe Bar 20112012; MMs = Medmerry 1993-2002. Note that C79, C78, S04, HI and S01 have multiple markers to show the range of uncertainty in the boundary conditions. Where sensitivity simulations have been carried out with equal wave steepness, error bars indicate the range of simulated $\mathrm{Q}_{\mathrm{crest}}$ and $\mathrm{BI}$ values. Note that the vertical scale in Figure 2 is logarithmic. Figure adapted from McCall et al. (2013).

- Breach and severe overwash (upper left panel) - HS, BE10 and C79 are classified as barrier breaching or severe overwash events (Figure 2 - upper panel). HS and BE10 showed significant lowering and retreat of the crest and flooding of the hinterland. C79 also showed severe flooding of the hinterland and lowering of the crest, but no barrier retreat. XBeach predicts overtopping discharge rates greater than $1001 \mathrm{~m}^{-1} \mathrm{~s}^{-1}$ at HS and BE10, and over $20-1001 \mathrm{~m}^{-1} \mathrm{~s}^{-1}$ at C79. All three events would be classed as overwash events in the XBeach model according to the threshold values found in the model calibration. 
Although HS and BE10 are both below the BIM overwash threshold, C79 is located above the threshold curve and would therefore not be predicted to be an overwash event by the BIM.

- Overwash damage to the back barrier (upper right panel) - Overwash events are identified by damage on the back barrier and limited flooding of the hinterland. These events include C78, which caused some flooding behind the barrier, S01, which caused significant damage to the main road located on the barrier, and five separate storms between 1994 and 2000 at Medmerry (MMo). The XBeach model correctly predicts the possibility of overwash $\left(Q_{\text {crest }}>201 \mathrm{~m}^{-1} \mathrm{~s}^{-1}\right)$ at SL01, and overwash for two storm events at Medmerry. However, C78 and the three other Medmerry storms are predicted to have an overtopping discharge less than $20 \mathrm{l} \mathrm{m}^{-1} \mathrm{~s}^{-1}$ and would therefore incorrectly be classed as non-overwash events. None of the storms in this category would, however, be predicted as possible overwash events by the BIM.

- Overtopping and crest build-up (lower left panel) - Overtopping events are classified as events during which the crest builds up (increase in crest elevation), the extent of the morphological change just reaches the crest, or the documentation describes occasional waves overtopping the crest. These include S04, HI and BE1. The XBeach model predicts overtopping discharges less than $20 \mathrm{~m}^{-1} \mathrm{~s}^{-1}$ at all these sites and are therefore correctly classified as non-overwash events. The model does predict limited overtopping of the barrier crest $\left(2-201 \mathrm{~m}^{-1} \mathrm{~s}^{-1}\right)$ at SL04 and HI, which corresponds with the notion of occasional waves overtopping the crest.

- Beach erosion with no change to crest (lower right panel) - The final classification is for storm events which affected the beach, but did not reach the crest. These events are called erosion events, and include three storms at Medmerry (MMs), four storms at Loe Bar (LB), the four largest storms each year between 2007 and 2010 at Chesil Beach (C07) and BC1. In a similar fashion to the overtopping events, the overwash discharge hindcast by the XBeach model is less than $20 \mathrm{~lm}^{-1} \mathrm{~s}^{-1}$, and would therefore correctly be classified as non-overwash events. All events except the storms at Medmerry are predicted to have less than $2 \mathrm{l} \mathrm{m}^{-1} \mathrm{~s}^{-1}$ overtopping discharge, which corresponds with the notion of no waves reaching the crest.

The validation hindcast simulations show that the XBeach model correctly predicts the possibility of overwash in six out of ten overwash storms events. Although the absolute accuracy of the XBeach model overwash prediction is only $60 \%$ in this validation dataset, the XBeach model still appears to improve upon the BIM, which only identifies two overwash events. The majority of incorrect predictions in the XBeach model are for storm events at Medmerry (three incorrect predictions of erosion or overtopping instead of overwash and three incorrect predictions of overtopping instead of erosion), suggesting that the natural system at Medmerry is not well described by the XBeach model, or by the documented storm data.

\subsubsection{Comparison with field observations of barrier overwash}


The ability of the XBeach-G model to simulate gravel barrier overwash and rollback is examined through the hindcast of the morphodynamic response of the Sillon de Talbert barrier on the north coast of Brittany (Figure 3 - left panel) to a large sluicing overwash event caused by storm Johanna (10 March 2008). During this storm event, which occurred in conjunction with spring tide, offshore wave heights reached $9.5 \mathrm{~m}$ with peak wave periods of $16 \mathrm{~s}$, leading to barrier rollback of approximately $15 \mathrm{~m}$ along the central section of the barrier (see Stéphan et al. (2012) and Stéphan et al. (2010) for a detailed description of this storm event and its impact on the barrier).
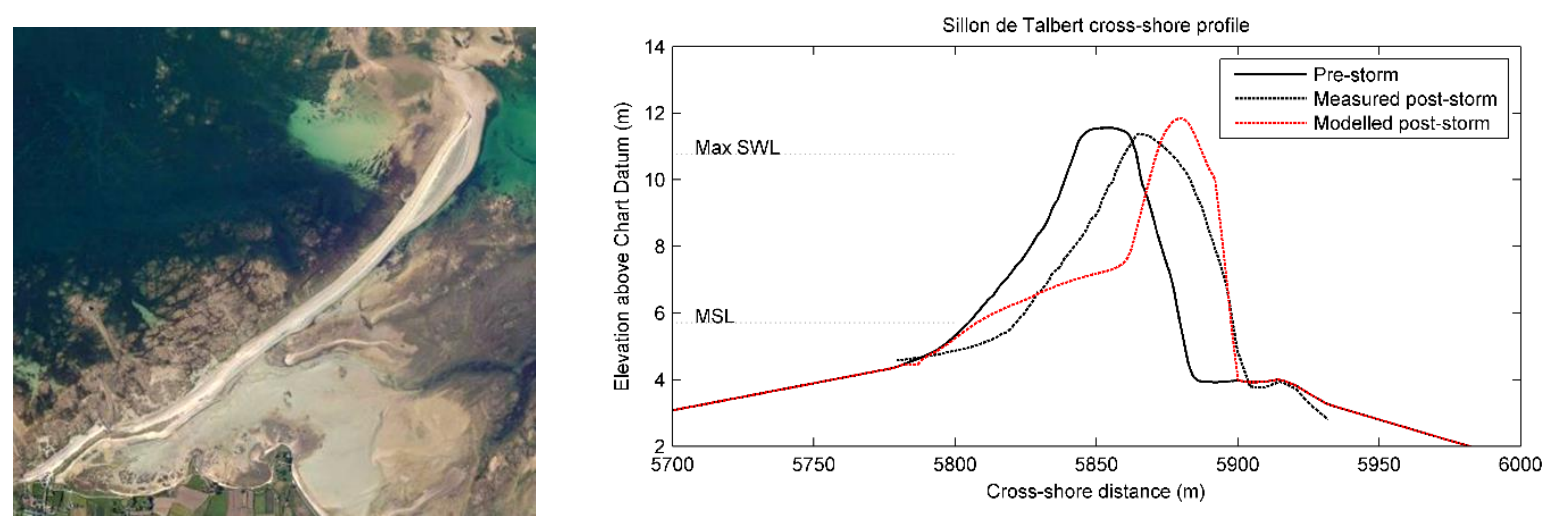

Figure 3 - Left panel shows aerial photograph of the 3-km long gravel barrier of Sillon de Talbert on the north coast of Brittany, France (Source: Bingmap). Right panel shows cross-shore profile of Sillon de Talbert six months prior to storm Johanna (solid black line), cross-shore profile measured six months after the storm (dashed black line) and computed post-storm cross-shore profile (solid orange line). The black dotted lines indicate mean sea level and the maximum still water level reached during storm Johanna.

The impact of storm Johanna on the barrier is modelled in XBeach-G using topographic, bathymetric and hydrodynamic forcing conditions provided by l'Université de Bretagne Occidentale (Stéphan and Suanez, pers. corr.). Topographic data of the barrier consist of supratidal and intertidal DGPS measurements of the barrier measured in September 2007 (prior to storm Johanna) and September 2008 (post storm Johanna; Stéphan, pers. corr.). These data are supplemented with LiDAR data of the intertidal beach measured in 2002 (Boersma and Hoenderkamp, 2003) and bathymetry data provided by the Service Hydrographique et Océanographique de la Marine. Time series of the storm surge level were derived from surge measured at the Roscoff tide gauge, located approximately $65 \mathrm{~km}$ from the study site, alongside tidal predictions at the location of the barrier. Wave conditions offshore of the barrier were extracted from a nested WAVEWATCH III model, forced by ECMWF wind fields. Model validation results on buoys off Brittany indicate an overall RMSE of $12 \%$ for wave height with a bias less than 2\% (Ardhuin and Accensi, 2011).

For the purpose of this study, one cross-shore transect in the central section of the Sillon de Talbert barrier is modelled in XBeach-G. The simulation is started at the first low tide of 10 March 2008 and runs until the first low tide of 13 March 2008. Wave, tide and surge boundary conditions derived from the data provided by l'Université de Bretagne Occidentale are imposed at an offshore depth of $20 \mathrm{~m}$ below MSL, see Figure 4. 
Since no quantitative data are available on the grain size and hydraulic conductivity of the barrier, the median grain size is estimated to be $8 \mathrm{~cm}$ (cf., Chanson, 2006), and the hydraulic conductivity $\left(K_{\text {lam }}\right)$ and critical Reynolds number for turbulence are set to $0.40 \mathrm{~m} \mathrm{~s}^{-1}$ and 80 , respectively, in analogue to the value found experimentally by Heijne and West (1991) for Portland, Chesil Beach. Following calibrated values found for Chesil Beach, the sediment friction factor $\left(f_{s}\right)$ is set to 0.01 and phase lag angle $(\varphi)$ is set to $25^{\circ}$.

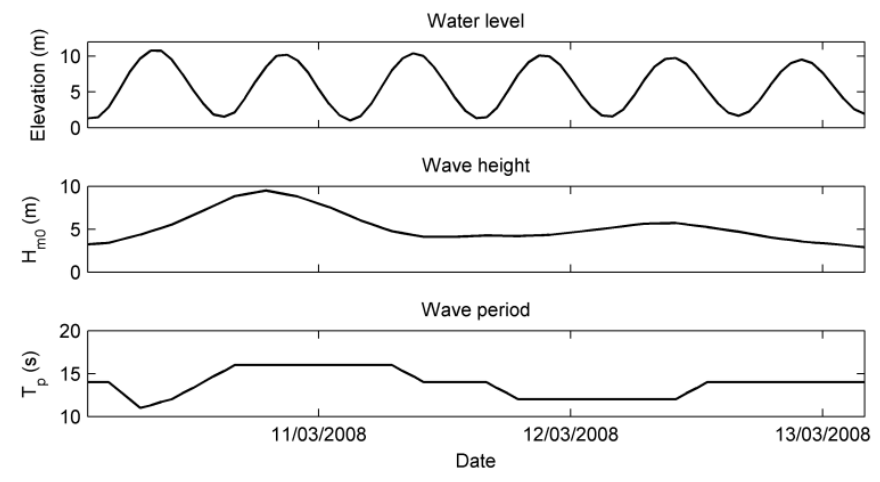

Figure 4 - Time series of tide and surge levels (top panel), significant wave height (centre panel) and peak wave period (bottom panel) applied in the XBeach-G simulation of storm Johanna.

The cross-shore profile change due to storm Johanna, simulated by XBeach-G is shown in Figure 3 (right panel) alongside the cross-shore profile measured six months after the storm (September 2008). Due to the large duration between simulated storm and the post-storm measurements, the modelled cross-shore profile change cannot be directly compared to the measured change. However, the observed barrier rollback can be attributed to storm Johanna, which was the largest storm event in this period (Stéphan et al., 2010). In a qualitative sense, the result shows that the model is able to reproduce the observed barrier rollback behaviour well, with a clear retreat of the supratidal and upper intertidal barrier.

In a quantitative sense, the model predicts bulk morphological change parameters well. The computed washover volume in the XBeach-G model is $138 \mathrm{~m}^{3} \mathrm{~m}^{-1}$, compared to $129 \mathrm{~m}^{3} \mathrm{~m}^{-1}$ found in the measurements, where washover volume is defined as the volume of material exceeding the initial bed level landward of the crest. The landward movement of the centre of mass of the gravel barrier above its base at an elevation of $4 \mathrm{~m}$ in the XBeach-G model is $14.1 \mathrm{~m}$, close to the $15.7 \mathrm{~m}$ found in the measurements. The accuracy of the bulk parameters is represented by a high Brier Skill Score (0.74) for the computed bed level change compared to the measured bed level change.

Despite good representation of the bulk morphological change parameters characterising the gravel barrier response, it is clear that the model does not represent the details of the post-storm profile equally well. The landward migration of the barrier crest is overestimated by approximately $10 \mathrm{~m}$ (57\% of the measured migration) and the model predicts slight increase in the crest height $(0.5 \mathrm{~m})$, instead of a slight lowering $(0.2 \mathrm{~m})$ found in the measurements. Finally, the development of the lower intertidal section of the gravel 
barrier is not well represented, which may in part be due to the long period between the storm and the poststorm profile measurements that is not simulated in the XBeach-G model, during which waves may have restructured this part of the profile. It should be noted that due to uncertainties in the forcing conditions (wave height and period) and barrier composition (grain size and hydraulic conductivity), as well as the duration between the pre-storm and post-storm survey, the model was not calibrated further to better reproduce the observed barrier profile.

\section{Graphical User Interface}

To encourage the use of XBeach-G for practical application by coastal managers, a Graphical User Interface (GUI) was developed that enables users to setup, run and analyse XBeach-G models. This GUI is built as a plugin of the Delta Shell framework described by Donchyts et al. (2010).

\subsection{Input}

Figure 5 gives an overview of the model views the XBeach-G GUI offers for specifying various kinds of input. The views enable specification of the initial situation, as well as hydrodynamic forcing at the offshore boundary and calculation parameters. This functionality is covered by the following views:

- Profile - Allows the user to specify the initial cross-shore (bed) profile of the calculation. In 'characteristics' mode, the user can enter morphometric characteristics of a gravel barrier (e.g., barrier height, width of the crest, beach gradient) on the basis of which the GUI designs an initial barrier profile. In 'Coordinates' mode, the user is allowed to specify the profile by means of manually entering crossshore and elevation coordinates. A profile file with coordinates can be directly imported as well. The GUI automatically generates a computational grid that best fits the initial profile and can be steered in this view.

- Tide - Provides tools to specify a time series of the water level at the offshore boundary of the model. A tidal signal can be created by means of a tide generation dialog box in which phase and amplitude can be specified, and a constant storm surge level can be added to the tidal signal. Alternatively, the water level time series can be entered manually or imported.

- Waves - Consists of a table that shows a time series of spectral specification of incident waves that will be used at the offshore boundary. A single wave spectrum or a time series of wave spectra can be entered. The spectral parameters to be specified include significant wave height $H_{s}$, peak wave period $T_{p}$, JONSWAP peak enhancement factor $\gamma$ and directional spreading $S$. A bi-modal wave spectrum can be specified by defining two sets of values for $H_{s}, T_{p}, \gamma$ and $S$. 
- Parameters - Offers the ability to specify values for time management (run duration and time step), initial conditions (groundwater level and elevation of bottom of aquifer), sediment characteristics (sediment size and hydraulic conductivity), option to update morphology or not, and sediment transport parameters.

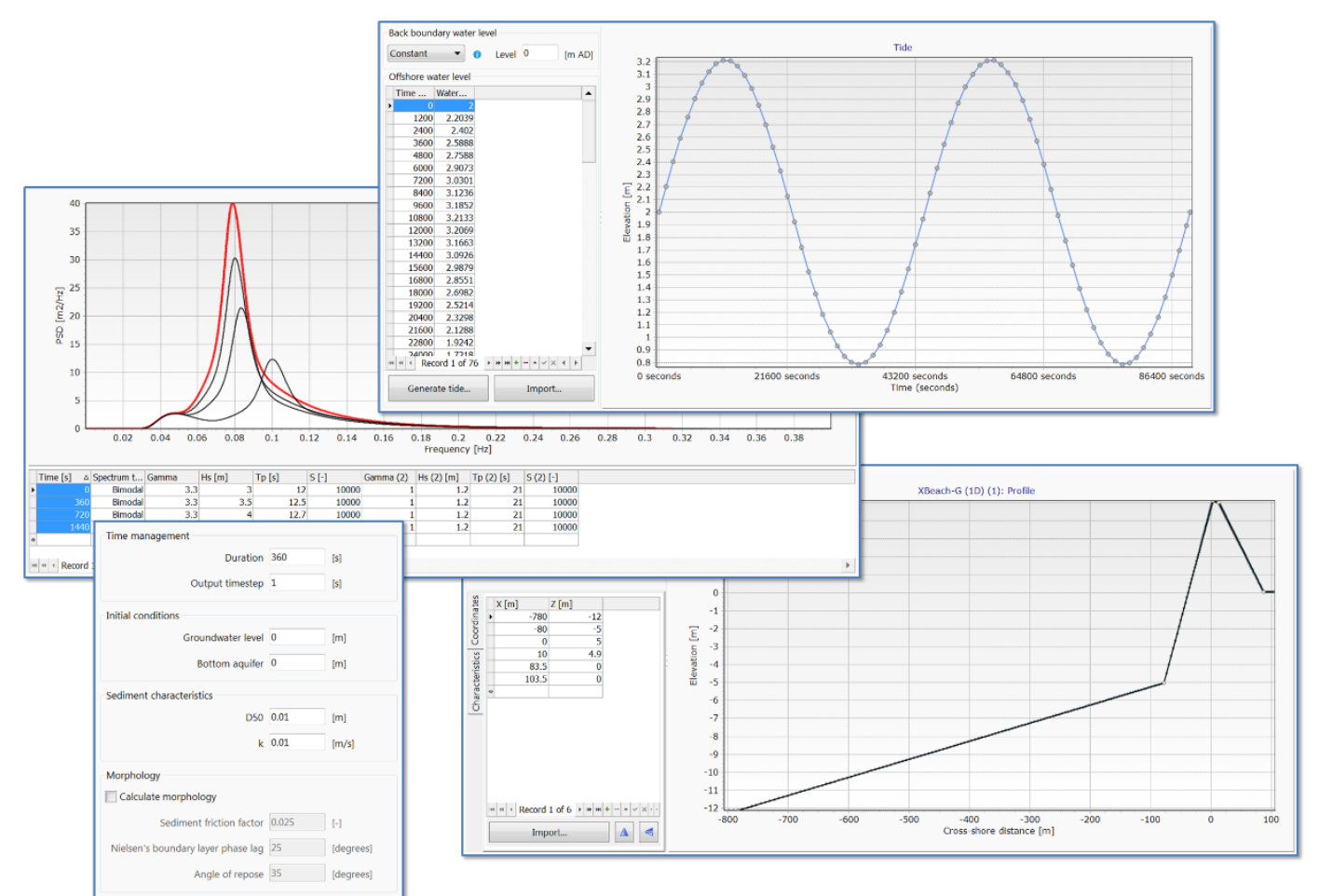

Figure 5 - An overview of the GUI views that allow specifying input for an XBeach-G model. It includes profile specification (lower-right corner), tide specification (upper-right corner), wave spectra time series (middle left) and additional parameters (lower-left corner).

\subsection{Output}

Once the specified model has been run, the XBeach-G GUI offers tools to analyse the model results. Figure 6 shows two of the available output screens, consisting of:

- Cross-shore - Provides a cross-shore slice of the calculated output at a specific point in time. Time navigation controls add the possibility to navigate through time and visualize the development of the output variables over the cross-section in time. A very large selection of output variables are available for plotting (e.g., water surface, ground water level, cross-shore velocity, water discharge across the barrier).

- Time series - Shows the development of the output variables in time at a specific location along the profile. When opening both Cross-shore and Time series views simultaneously, the user can navigate the cross-shore position of the time series output in the Cross-shore output view. As in the Cross-shore view, a very large of output variables can be selected for plotting. 


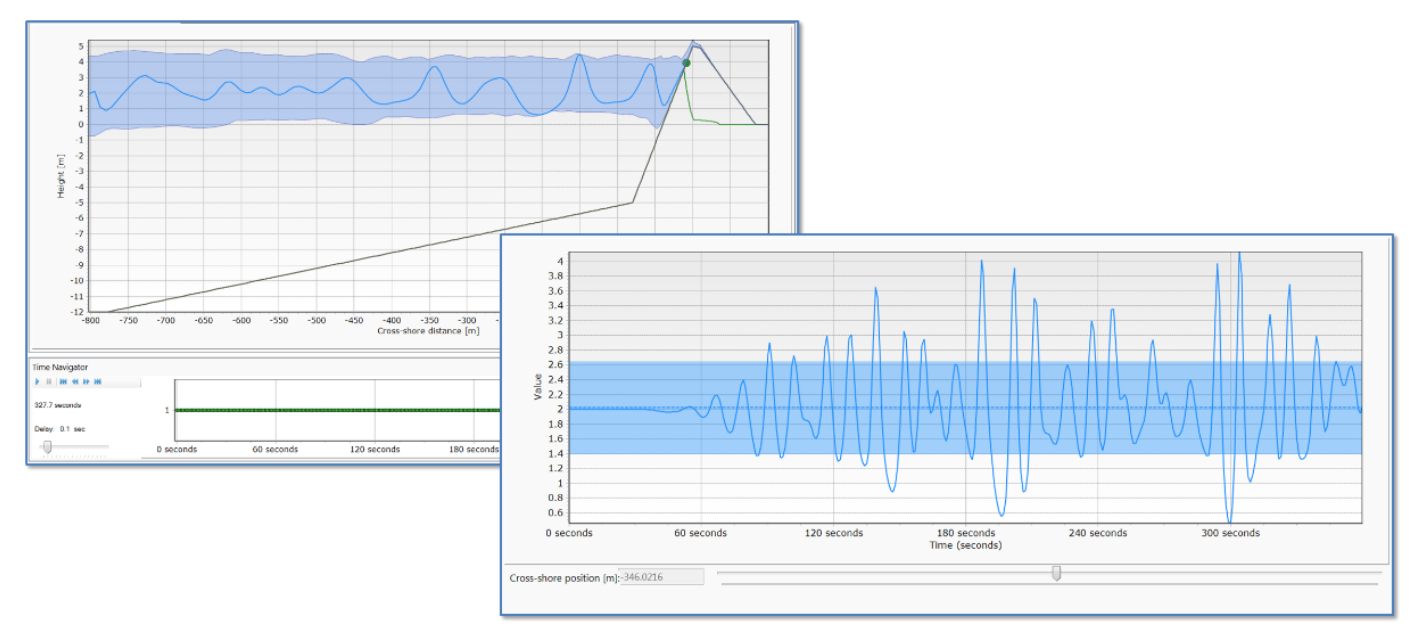

Figure 6 - An example of two output screens the GUI offers to analyse the output of XBeach-G model runs. Left view represents the Cross-shore view, showing a cross-shore section of the output (gravel barrier in dark green; water surface elevation in blue; beach groundwater table across the barrier in light green; and the instantaneous shoreline or runup indicated by the green circle) at $\mathrm{t}=304.5 \mathrm{~s}$, which can be adjusted to using the time navigator controls at the bottom. The right view represents the Time series view, showing an example of the water surface elevation time series at a specific location $(\mathrm{x}=-554.5 \mathrm{~m})$, which can be adjusted using the cross-shore position controls at the bottom.

\subsection{Accessing the XBeach-G code and running the model outside the GUI}

Apart from running XBeach-G calculations inside the GUI environment, it is also possible to run calculations without the help of the GUI. To that end the user can specify model input in a text file and provide that to the calculation engine. Running a calculation without the GUI offers more flexibility to change settings or input specification as some model settings are not accessed through the GUI. The GUI offers an export option that allows the user to export a model setup that was generated through the GUI. The model input, including the calculation engine will then be written to the specified output location. This enables the user to run XBeach-G calculations elsewhere, for example on a calculation cluster, or write a script that uses the input file to run calculations in batch mode, changing one or more of the input parameters. When finished running these calculations, it is also possible to import the calculation results back into the GUI environment. XBeach-G calculation output can be stored in a single file. When using the import functionality for the results, this output file is coupled to a model setup already specified in the GUI environment (and for example also used to export the model setup). Calculation results can then be analysed as if the calculations were run inside the environment of the GUI.

\section{Model application}

\subsection{Reshaping the Slapton Sands barrier to prevent overwash}

The 5-km long gravel barrier system of Slapton Sands is located on the south Devon coast (Figure 7 - left panel). A road runs along the crest of the barrier and the barrier is backed by a freshwater lagoon. The 
barrier was overtopped in 2001 and 2004, and overwashed in 2013, and there is mounting concern over the long-term integrity of the barrier system, and therefore the viability of the road and the freshwater status of the lagoon. In this case study we will use XBeach-G to look at the response of the barrier systems to extreme wave and water-level conditions, and explore the efficacy of two types of gravel nourishments as a means of preventing overwash.
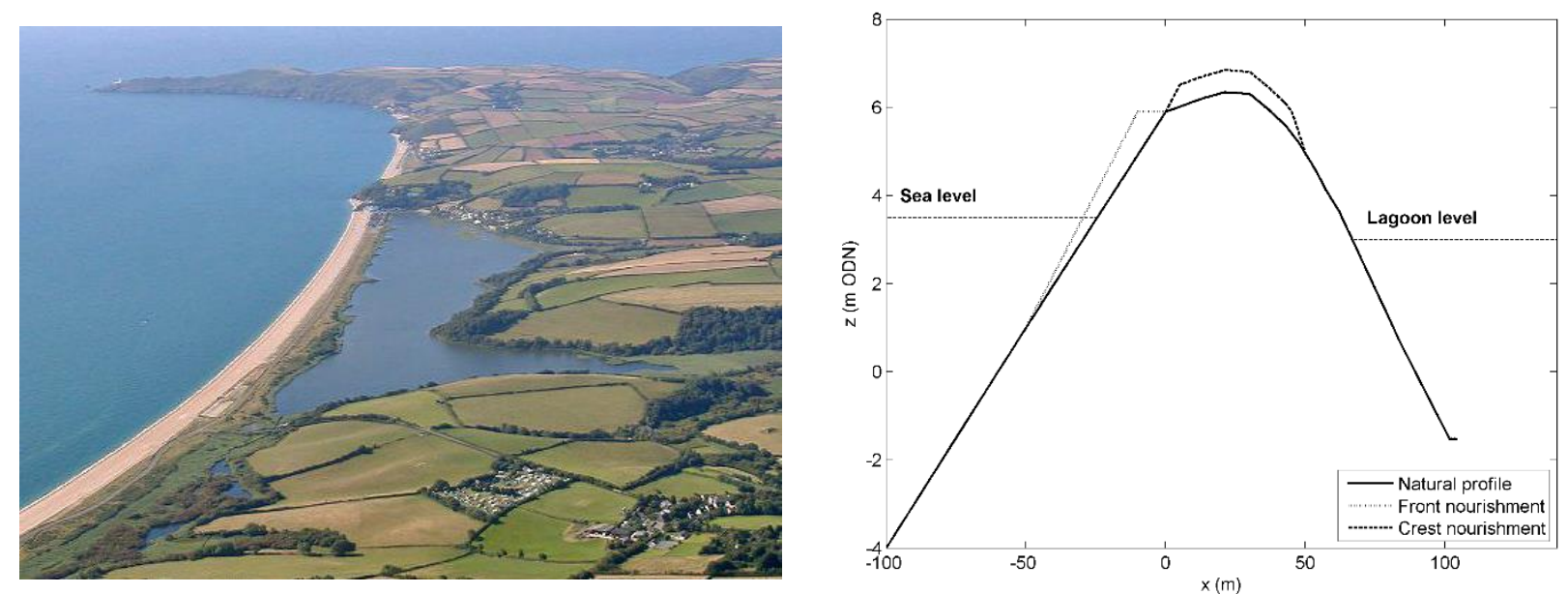

Figure 7 - Left panel shows aerial photograph of the 5-km long gravel barrier of Slapton Sands on the south coast of Devon, UK. Right panel shows the natural profile of Slapton Sands and the modified profile due to nourishment placed on the front and the top of the barrier. Both nourishments represents $25 \mathrm{~m}^{3}$ per unit m beach width. ODN refers to Ordnance Datum Newlyn which is c. $0.2 \mathrm{~m}$ above mean sea level in England.

For the model simulations the actual profile of Slapton Sands, representative of the central section of the barrier system, was uploaded with the seaward profile extrapolated to a depth of $-12 \mathrm{~m}$ ODN (Ordnance Datum Newlyn, which is c. $0.2 \mathrm{~m}$ below MSL) with a seaward slope of $1 / 10$. The elevation of the barrier crest is c. $6 \mathrm{~m}$ ODN and the supratidal part of the barrier is c. $50 \mathrm{~m}$ wide. The existing barrier profile was modified by adding $25 \mathrm{~m}^{3}$ per unit $\mathrm{m}$ beach width to the profile (Fig. 7 - right panel). In the first case, the sediment was added to the front of the barrier in the form of a wedge, extending the $6 \mathrm{~m}$ ODN contour $10 \mathrm{~m}$ seaward and increasing the gradient of the upper barrier to $1 / 8$. In the second case, a $0.5-\mathrm{m}$ cap was placed over the 50-m wide barrier crest region.

All three barrier profiles were subjected to the same extreme wave and water-level conditions, and with the same model parameters. The sea level was $3.5 \mathrm{~m} \mathrm{ODN} \mathrm{(spring} \mathrm{high} \mathrm{tide} \mathrm{plus} \mathrm{a} \mathrm{1:50} \mathrm{year} \mathrm{storm} \mathrm{surge),} \mathrm{the}$ lagoon water level was $3 \mathrm{~m}$ ODN (actual mean lagoon level), aquifer depth was $-5 \mathrm{~m}$ ODN (approximate elevation of underlying peat layer), and the wave conditions were characterised by significant wave height $H_{s}$ of $5 \mathrm{~m}$ and a peak wave period $T_{p}$ of $12 \mathrm{~s}$. The other input parameters used were: sediment size $D_{50}=$ $0.01 \mathrm{~m}$; hydraulic conductivity $K_{\text {lam }}=0.01 \mathrm{~m} \mathrm{~s}^{-1}$; and the default values for the sediment transport parameters. The run length for each test was $3600 \mathrm{~s}(1 \mathrm{hr})$, to represent a sufficient period of time around a high tide to ensure significant morphological change occurs and robust extreme runup estimates are obtained, and each of the three XBeach-G models was run with and without morphodynamic updating; the latter 
simulations were carried out to facilitate determining the effect of the morphology on the hydrodynamics without the confounding effects of changing morphology. It is noted that the morphodynamic modelling was conducted without prior calibration of the relevant sediment transport parameters; therefore, the results should be considered qualitative, not quantitative. In contrast to the simulations comparing observed with modelled runup, which were repeated 10 times with different random seeds of the wave spectra, the barrier response simulations were only conducted once for each case.
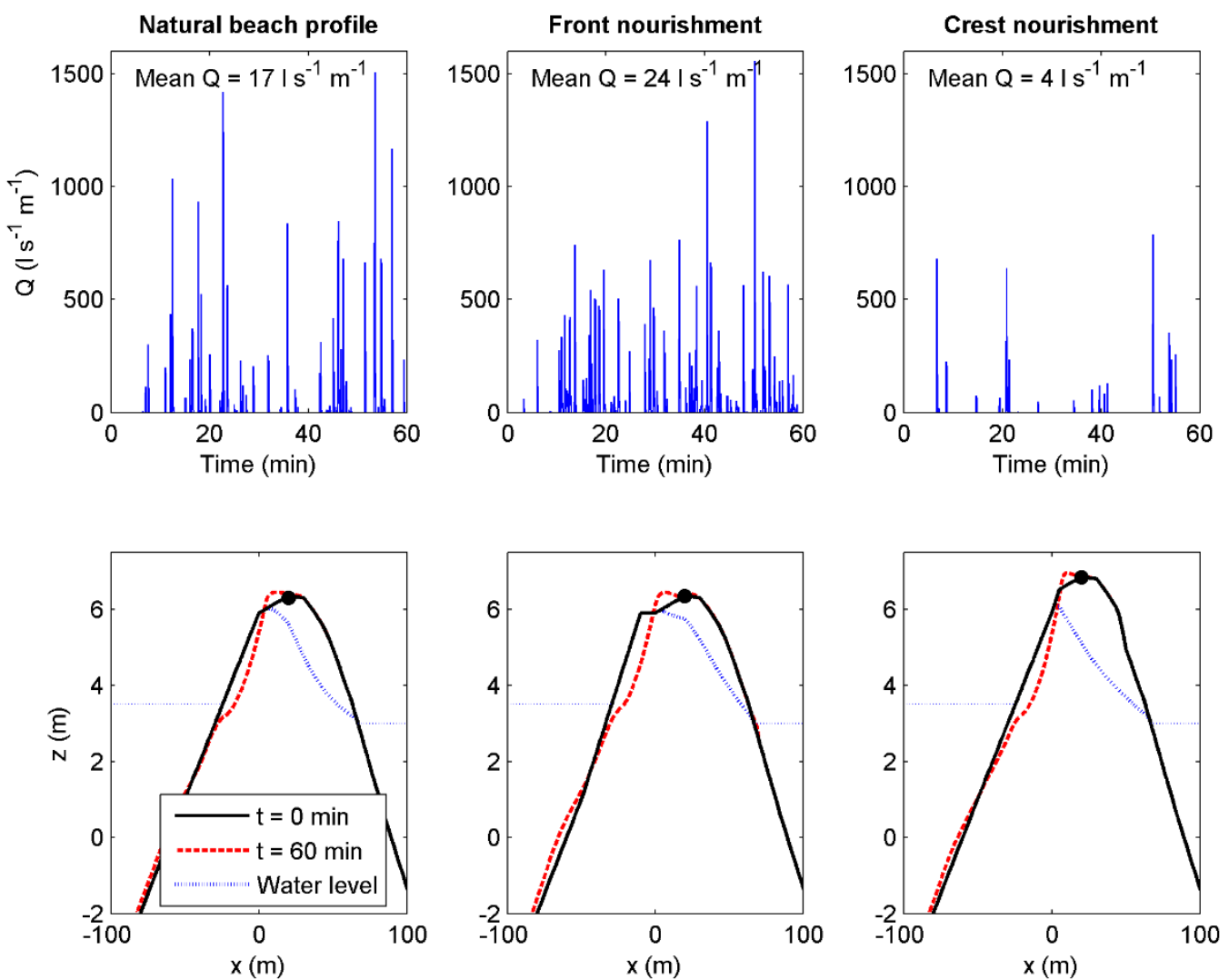

Figure 8 - Modelled overwash and morphological response of the Slapton Sands gravel barrier when subjected to extreme wave and water-level conditions. Top panels show the 1-hr overwash discharge time series at the barrier crest ( $x=20 \mathrm{~m}$; indicated by the solid circle in the lower panels) for the three barrier profiles for runs without morphodynamic updating; bottom panels show the morphological response. Left panels represent the natural Slapton Sands barrier profile; middle panels represent the natural profile with nourishment added to the front of the barrier; and right panels represent natural profile with nourishment added to the top of the barrier.

The top panels of Figure 8 show the 1-hr time series of modelled barrier overwash at the barrier crest location $(x=20 \mathrm{~m})$. These runs were conducted without morphodynamic adjustment to purely look at the effect of different morphology on hydrodynamics. Perhaps surprisingly, the model run with the nourishment placed to the front of the barrier actually enhanced overwash intensity: more frequent overwashes and larger mean overwash volume $\left(241 \mathrm{~s} \mathrm{~s}^{-1} \mathrm{~m}^{-1}\right.$ compared to $17 \mathrm{~s}^{-1} \mathrm{~m}^{-1}$ for the natural profile). Placing the nourishment on the crest of the barrier reduced overwash frequency and mean overwash volume $\left(4 \mathrm{~s} \mathrm{~s}^{-1} \mathrm{~m}^{-1}\right)$. The model runs with morphodynamic updating (lower panels of Figure 8) all show retreat of the front of the barrier, significant deposition across the lower part of the profile and on the barrier crest, and a very small amount of backbarrier deposition (c. $0.02 \mathrm{~m}$ ). Upper beach erosion and deposition across the lower part of the profile is 
largest for the profile with the nourishment to the front of the barrier. The barrier retreat for the upper beach of the profile ( $z=3-6 \mathrm{~m} \mathrm{ODN}$ ) is c. $7 \mathrm{~m}$ for the natural profile and the profile with crest nourishment, and c. $12 \mathrm{~m}$ for the profile with the front nourishment, leaving the upper part of the latter profile c. $5 \mathrm{~m}$ seaward of the other two profiles.

The reason for the enhanced overwash intensity and morphological change for the barrier profile with the front nourishment is that the steepening of the profile caused by the nourishment (from 1/10 to 1/8) leads to an increase in the vertical runup. This is a very important factor that should be taken into account when using nourishment (or reshaping) as a coastal protection measure. The modelling further suggests that fixing the crest position of a retreating gravel barrier (e.g., due to sea-level rise) is unsustainable in the long run, because a steeper barrier becomes increasingly vulnerable to overwash.

\subsection{Role of the shape of the wave spectrum}

Along the south coast of England, it has been observed that coastal flooding caused by overwash is more likely to occur when energetic wind wave conditions coincide with a significant amount of swell wave energy; in other words, when the wave spectrum is bimodal (Bradbury, pers. comm.). The importance of swell energy and bimodality of the wave spectrum has also been highlighted by the work of Polidoro et al. (2013). Addition of a swell peak to a wind wave spectrum will automatically represent an increase in the wave energy and wave period, and therefore runup, and it is therefore unclear whether the observed increase in likelihood of overwash under bimodal wave conditions is simply due to an increase in wave energy and wave period, or is related to the bimodal nature of the wave spectrum. XBeach-G offers the opportunity to investigate whether runup and overwash characteristics are significantly affected by the shape of the wave spectrum by allowing model simulations with differently shaped spectra (unimodal and bimodal), but identical significant wave height and mean wave period $\left(H_{s}\right.$ and $\left.T_{m}\right)$.

A total of 8 XBeach-G models were set-up using the 'idealised' barrier profile (cf. Figure 5 and 6 ), but with the water depth at the start of the profile extended from 15 to $20 \mathrm{~m}$ and the barrier height increased from 5 to $6 \mathrm{~m}$ ), the input parameters listed in Table 1 , a sediment size $D_{50}$ of $0.01 \mathrm{~m}$, a hydraulic conductivity $K$ of $0.01 \mathrm{~m} \mathrm{~s}^{-1}$, and the default values for the sediment transport parameters. The run length for each test was $3600 \mathrm{~s}$ ( $1 \mathrm{hr}$ ). The four different test wave conditions represent widely-varying spectral shapes (Figure 9), but identical significant wave height $H_{s}$ and mean wave period $T_{m}$ (Table $1 ; T_{m}$ was computed as $m_{1} / m_{0}$, where $m_{1}$ and $m_{0}$ represent the first and zeroth moment of the wave spectrum, respectively). The peak periods $T_{p}$ are also different, but it should be pointed out that for the bimodal wave condition of test T3 there is not a single spectral peak (moreover, spectral peak period strongly depends on the degree of smoothing of the wave spectrum). 
Table 1 -XBeach-G model parameters for investigating the influence of the shape of the wave spectrum on wave runup and overwash characteristics.

\begin{tabular}{|l|l|l|l|l|l|l|l|l|l|}
\hline \multicolumn{9}{|c}{ Wind wave } & \multicolumn{7}{c|}{ Combined wave } \\
\hline Test & $\begin{array}{l}H_{s 1} \\
(\mathrm{~m})\end{array}$ & $\begin{array}{l}T_{p 1} \\
(\mathrm{~s})\end{array}$ & $\begin{array}{l}H_{s 2} \\
(\mathrm{~m})\end{array}$ & $\begin{array}{l}T_{p 2} \\
(\mathrm{~s})\end{array}$ & $\begin{array}{l}H_{s} \\
(\mathrm{~m})\end{array}$ & $\begin{array}{l}T_{p} \\
(\mathrm{~s})\end{array}$ & $\begin{array}{l}T_{m} \\
(\mathrm{~s})\end{array}$ & $\begin{array}{l}\text { MSL } \\
(\mathrm{m})\end{array}$ & $\begin{array}{l}\text { Morph. } \\
\text { updating }\end{array}$ \\
\hline T1A & 5.0 & 10.0 & & & 5.0 & 10.0 & 8.6 & 0 & No \\
\hline T1B & 5.0 & 10.0 & & & 5.0 & 10.0 & 8.6 & 3.5 & Yes \\
\hline T2A & 4.5 & 9.3 & 2.2 & 15.0 & 5.0 & 9.3 & 8.6 & 0 & No \\
\hline T2B & 4.5 & 9.3 & 2.2 & 15.0 & 5.0 & 9.3 & 8.6 & 3.5 & Yes \\
\hline T3A & 4.0 & 8.4 & 3.0 & 15.5 & 5.0 & $8.5 / 15.5$ & 8.6 & 0 & No \\
\hline T3B & 4.0 & 8.4 & 3.0 & 15.5 & 5.0 & $8.5 / 15.5$ & 8.6 & 3.5 & Yes \\
\hline T4A & 3.55 & 7.3 & 3.55 & 16.0 & 5.0 & 16.0 & 8.6 & 0 & No \\
\hline T4B & 3.55 & 7.3 & 3.55 & 16.0 & 5.0 & 16.0 & 8.6 & 3.5 & Yes \\
\hline
\end{tabular}

During test series A (T1A-T4A), the water level was such that the swash motion was limited to the seaward slope of the barrier (MSL at $0 \mathrm{~m}$; no overwash) and the morphology was not updated. These tests were purely designed to investigate the effect of wave spectral shape on wave runup. The results shown in the lower-left panel of Figure 9 reveal that as the swell-wave contribution increases from 0 to $50 \%$, whilst keeping the overall wave energy level and the mean wave period the same, the maximum wave runup $R$ increases from $3.35 \mathrm{~m}$ to $5.12 \mathrm{~m}$ (50\% increase). The maximum wave runup is here defined as the average of the 10 highest runup events that occurred during the 1-hr model simulation. This estimate of extreme runup level was found to be similar to, but more 'stable' than the $2 \%$ exceedence level.

During test series B (T1B-T4B), the water level raised to MSL at $3.5 \mathrm{~m}$ to ensure overwash occurred and morphodynamic updating was turned on. These tests were designed to investigate the effect of wave spectral shape on overwash characteristics and morphological change due to overwash. The morphology before and after the model simulations for the four test wave conditions is presented in Figure 10. During all model simulations, erosion of the upper seaward slope of the barrier occurs accompanied by deposition across the lower seaward slope (offshore sediment transport). The morphological response of the crestal region of the barrier differs, however, significantly between the different runs. During the test with unimodal wave conditions (T1B), some overwashing occurs, resulting in sediment deposition on the top of the barrier and a modest increase in the barrier crest height. However, for the tests with bimodal wave conditions (T2B-T4B) the increased intensity of the overwash process leads to enhanced shoreline retreat, barrier crest lowering and backbarrier deposition. The overwash intensity was quantified by determining the mean overwash volume across the barrier crest (at $x=0 \mathrm{~m}$ ) and shows an almost ten-fold increase from $0.015 \mathrm{~m}^{3} \mathrm{~s}^{-1} \mathrm{~m}^{-1}$ during T1B to $0.139 \mathrm{~m}^{3} \mathrm{~s}^{-1} \mathrm{~m}^{-1}$ during T4B (Figure 9 lower-middle panel). 

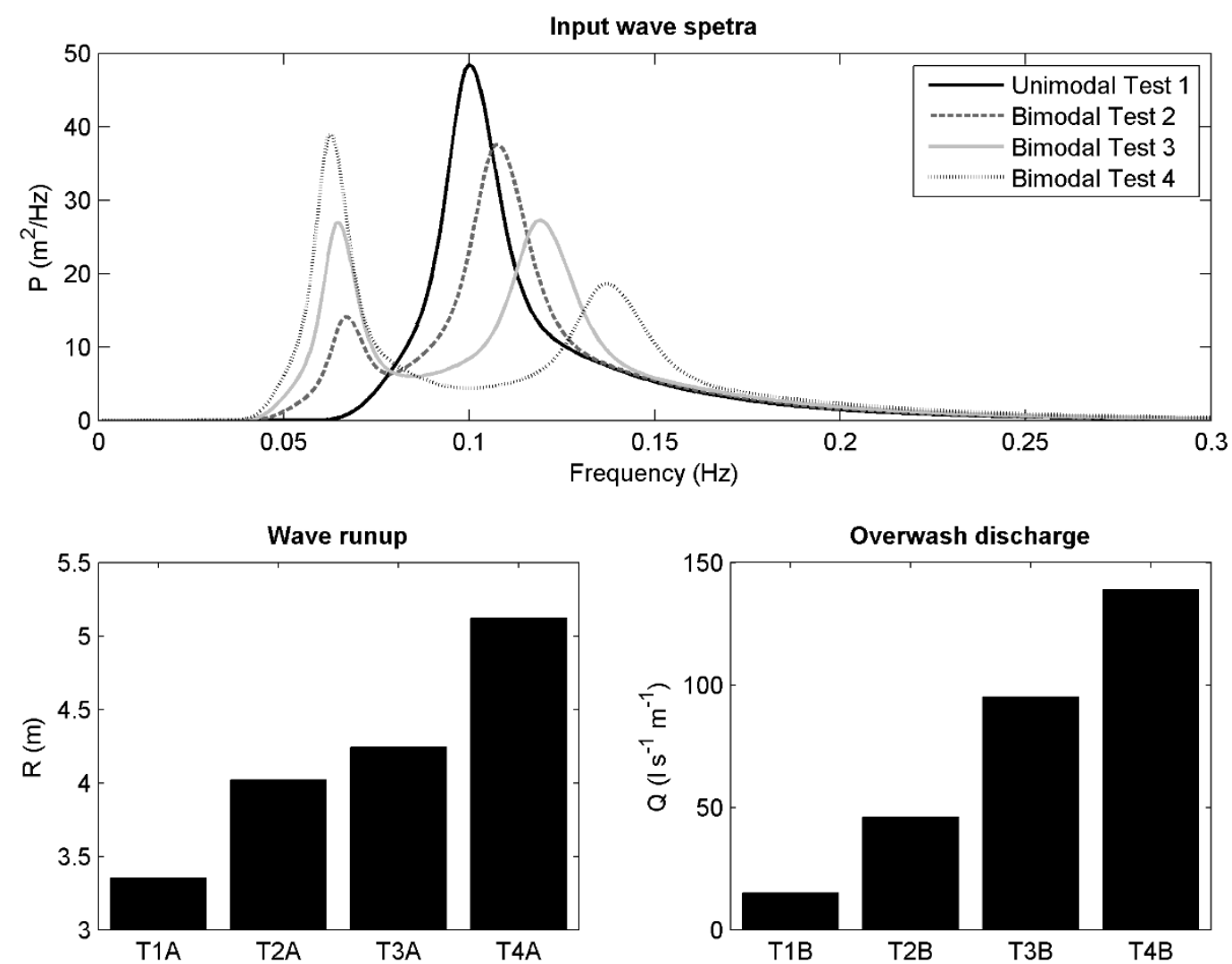

Figure 9-Top panel shows the input wave spectra for investigating the role of spectral shape on wave runup and overwash characteristics (for wave parameters refer to Table 1). The bottom panels show, from left to right, maximum wave runup $\mathrm{R}$ for test series A (T1A-T4A; no morphodynamic updating) and mean overwash discharge $\mathrm{Q}$ across the crest of the barrier at $\mathrm{x}=0 \mathrm{~m}$ for test series $B(T 1 B-T 4 B$; with morphodynamic updating).

These model simulations highlight significantly different runup and overwash characteristics for different wave spectral shapes, but identical $H_{s}$ and $T_{m}$. Wave runup and barrier overwash increases dramatically as the contribution of swell waves to the overall wave energy spectrum is increased. The increased runup and overwash cannot be quantified by the peak wave period $T_{p}$ (which decreases from $\mathrm{T} 1$ to $\mathrm{T} 2$ and is ambiguous for T3). The implication is that care should be taken in using runup predictors based on simple wave parameters (e.g., Stockdon et al., 2006).

\section{Model capabilities and limitations}

XBeach-G has been extensively validated for the prediction of storm-induced hydrodynamics (wave transformation, run-up, overtopping, overwash) on pure gravel beaches and is able to simulate observed morphological change on gravel beaches given correct model calibration. However, since XBeach-G is still under development, the model has important limitations that must be considered when applied to research, vulnerability and design projects. These limitations are discussed briefly below. 

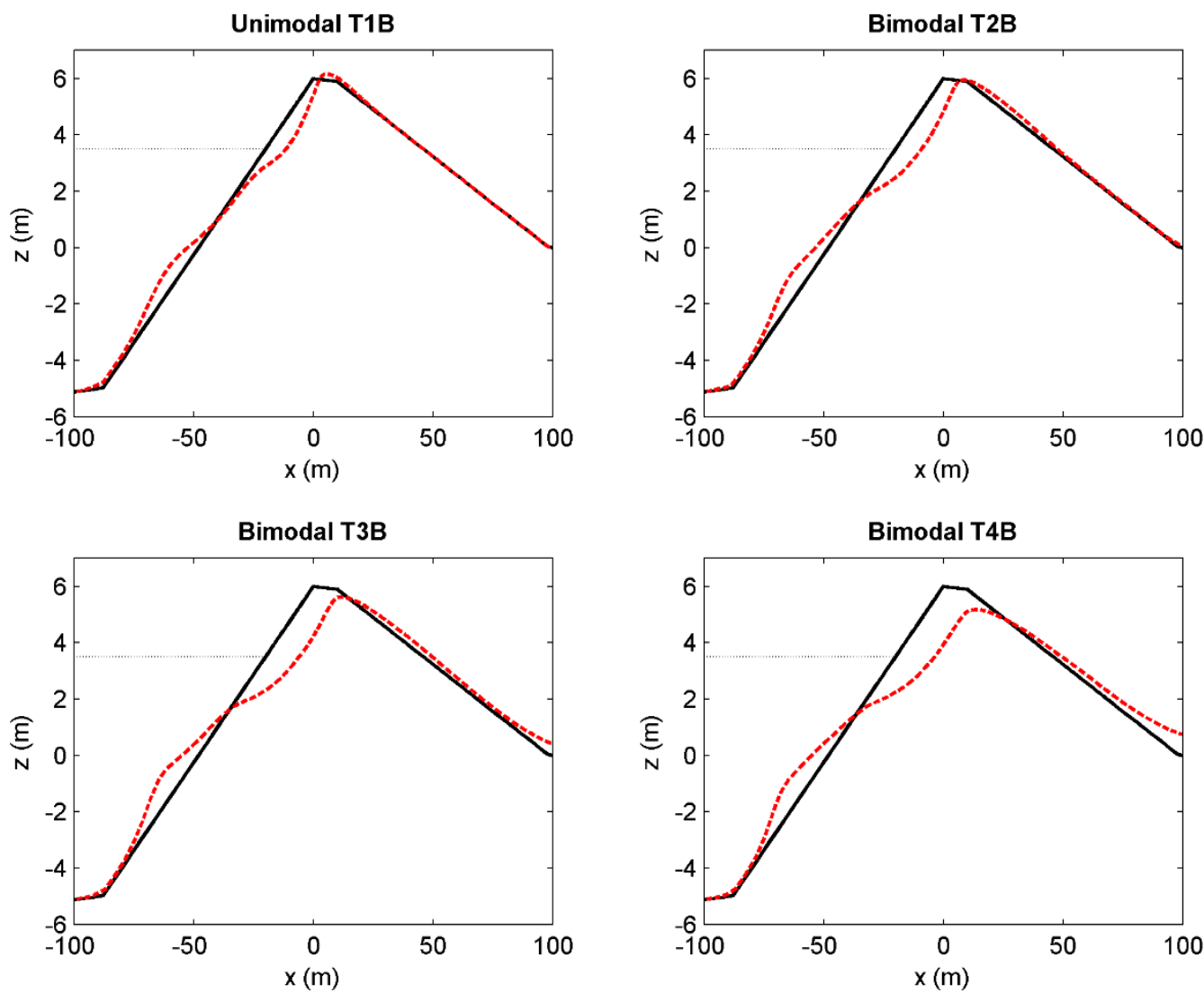

Figure 10 - Morphological response during 1-hour of overwash conditions for the wave conditions listed in Table 1. The black line represents the morphology at the start of the simulation and the red dashed line is the morphology at the end. The horizontal dotted line is MSL during the simulation.

- Morphodynamic calibration - Although XBeach-G has been shown to be capable of reproducing observed morphodynamic change at the validation sites discussed in this paper and in McCall et al. (in prep), calibration of the dominant sediment transport parameters will be required before application at other sites.

- Longshore processes - XBeach-G has at this stage only been developed and validated as a onedimensional cross-shore transect model. Although this is more computationally efficient than simulating processes in 2DH (area model), an important limitation of this schematisation is that the model assumes longshore uniformity in forcing conditions and beach geometry. This implies that XBeach-G will not compute longshore transports, and, importantly, will not take into account sediment gains and losses due to longshore transport gradients. It is not recommended to apply the XBeach-G model in wave conditions with a large angle of incidence ( $>30^{\circ}$ from shore-normal).

- Wave transformation - The wave module of the XBeach-G model has been shown to correctly model wave transformation in the nearshore zone for shallow to intermediate water depths. However, due to limitations in the processes modelled by the wave module (e.g., wind-driven wave growth) and numerical limitations of the wave module (e.g., numerical approximation of the vertical pressure distribution, numerical diffusion) the model cannot be used to accurately model wave transformation from deep water or from large distances from the shore. It is therefore recommended to apply 
XBeach-G in small relative water depths $(k d<3$, where $k$ is the wave number and $d$ is the water depth) and over limited cross-shore distances $\left(L_{\text {model }}<20 L_{\text {wave }}\right.$, where $L_{\text {model }}$ is the cross-shore model domain extent and $L_{\text {wave }}$ is the characteristic wave length).

- Mixed sand-gravel beaches - XBeach-G has been designed for use on pure gravel beaches and has not been tested on mixed and composite sand-gravel beaches. Although XBeach-G should be able to correctly compute wave transformation and wave run-up on sand-gravel beaches given correct schematisations for groundwater processes, the model does not contain sediment transport processes for (sandy) suspended sediment transport. The model is therefore currently not suitable for computing morphodynamic change on mixed sand-gravel beaches.

\section{Conclusions}

This paper presents an overview of one of the key results of the NUPSIG research project, which was aimed at developing the capability to predict the response of gravel beaches and barriers to extreme wave and water-level conditions. The XBeach-G model and accompanying GUI will allow end-users to investigate the safety of gravel beaches and barriers against storm erosion and flooding, and assist in the development of coastline management and flooding mitigation plans. Example case-studies discussed in this paper show the use of the XBeach-G model in accessing beach recharge schemes in terms of their effect of beach morphology during extreme conditions, and the use of the model in identifying the effect of the wave spectrum on storm wave overtopping thresholds. The XBeach-G model and GUI, as well as the XBeach-G model source code (Fortran95) are available for download on the XBeach project website (www.xbeach.org).

\section{Acknowledgements}

The research that lead to the development of XBeach-G was funded by two EPRSC grants awarded to the lead authors: New Understanding and Prediction of Storm Impacts on Gravel beaches (NUPSIG; EP/H040056/1) and Adaptation and Resilience of Coastal Energy Supply (ARCEoS; EP/IO35390/1). We would like to thank all members of the Coastal Processes Research Group who have contributed to the field efforts underpinning the numerical modelling. We would also like to thank the NUPSIG project partners for their contribution to the project: James Sutherland (HR Wallingford), Uwe Dornbusch (Environment Agency) and Travis Mason (Channel Coastal Observatory). Serge Suanez of the l'Université de Bretagne Occidentale kindly provided the beach profiles of Sillon de Talbert.

\section{References}


Ardhuin F and Accensi M, (2011) Etats de mer et agitation sur le fond dans la sous-région marine Manche, Mer du Nord DCSMM/EI/MMN. Ministère de l'Ecologie du Développement Durable des Transports et du Logement, Ref. DCSSM/EI/EE/MMN /1.1.7/2011, 5p.

Austin MJ and Masselink G, (2006) Swash and groundwater interaction on a steep gravel beach. Continental Shelf Research, 26, 2503-2519.

Boersma SM and Hoenderkamp K, (2003) Tregor, final report IFREMER, Amsterdam, 25 p.

Bradbury AP, Cope SN and Prouty, D.B., 2005. Predicting the response of shingle barrier beaches under extreme wave and water level conditions in Southern England. Proceedings of Coastal Dynamics, ASCE, Barcelona, Spain, pp1-14.

Bradbury AP, (2002) Predicting breaching of shingle barrier beaches - recent advances to aid beach management. $35^{\text {th }}$ MAFF (DEFRA) Conference of River and Coastal Engineers.

Buscombe D and Masselink G, (2006). Concepts in gravel beach dynamics. Earth Science Reviews, 79, 33 52.

Carter RWG and Orford JD, (1993) The morphodynamics of coarse clastic beaches and barriers: A shortand long-term perspective. Journal of Coastal Research, SI 15, 158-179.

Chadwick AJ, Karunarathna H, Gehrels W R, Massey A C, O’Brian D and Dales D, (2005) A new analysis of the Slapton barrier beach system. Maritime Engineering, 158, 147-161

Chanson, H, (2006) The Sillon de Talbert, Cotes d'Armor, North Brittany, France. Shore \& Beach 74, 2627.

Clarke S, Dodd N and Damgaard J, (2004) Modeling flow in and above a porous beach. Journal of Waterway, Port, Coastal and Ocean Engineering, 130(5), 223-233.

Darcy H, (1856) Les fontaines publiques de la ville de Dijon. Tech. Rep., Dalmont, Paris.

Donchyts G and Jagers B, (2010) DeltaShell - an open modelling environment. Proceedings of 2010 International Congress on Environmental Modelling and Software, Ottawa, Canada.

Fredsøe J and Deigaard R, (1992) Mechanics of Coastal Sediment Transport, World Scientific, pp392.

Halford K, (2000) Simulation and interpretation of borehole flowmeter results under laminar and turbulent flow conditions. In: Proceedings of the Seventh International Symposium on Logging for Minerals and Geotechnical Applications, Golden, Colorado. The Minerals and Geotechnical Logging Society, pp. 157168.

Heijne, I and West G, (1991) Chesil sea defence scheme. Paper 2: design of interceptor drain. Proceedings of the Institution of Civil Engineers. 90. 799-817.

Jennings R and Shulmeister J, (2002) A field based classification scheme for gravel beaches. Marine Geology, 186, 211-228.

Kirk TM, (1975) Mixed sand and gravel beaches: morphology, processes and sediments. Progress in Physical Geography, 4, 189-201. 
Komar PD, (2010) Shoreline evolution and management of Hawke's Bay, New Zealand: tectonics, coastal processes, and human impacts. Journal of Coastal Research, 26, 143-156.

López de San Román-Blanco B, Coates TT, Holmes P, Chadwick AJ, Bradbury A, Baldock TE, PedrozoAcuña A, Lawrence J and Grüne J, (2006) Large scale experiments on gravel and mixed beaches: Experimental procedure, data documentation and initial results. Coastal Engineering, 53, 349-362.

Lorang MS, (1991) An artificial perched-gravel beach as a shore protection structure. Proceedings Coastal Sediments, ASCE, 1916-1925.

Masselink G and Turner IL, (2012) Large-scale laboratory investigation into the effect of varying backbarrier lagoon water levels on gravel beach morphology and swash zone sediment transport. Coastal Engineering, 63, 23-38

McCall RT, Masselink G, Roelvink J, Russell PE, Davidson, M and Poate TG, (2012) Modeling overwash and infiltration on gravel barriers. Proceedings $33^{\text {rd }}$ International Conference on Coastal Engineering, ASCE, Santander, Spain.

McCall RT, Masselink G, Poate TG, Bradbury A, Russell PE and Davidson M, (2013) Predicting overwash on gravel barriers. In: Conley DC, Masselink G, Russell PE and O'Hare TJ (eds.), Proceedings 12th International Coastal Symposium, Plymouth, England, Journal of Coastal Research, SI65, 1473-1478.

McCall RT, Poate TG, Masselink G, Roelvink JA, Almeida LP, Davidson M and Russell PE, (2014) Modelling storm hydrodynamics on gravel beaches with XBeach-G. Coastal Engineering, 91, 231-250.

McCall RT, Masselink G, Poate TG and Roelvink JA, in preparation. Modelling storm morphodynamics on gravel beaches with XBeach-G.

Meyer-Peter E and Müller R, (1948) Formulas for bed-load transport. Proceedings of the 2nd Meeting of the International Association for Hydraulic Structures Research, 39-64.

Moses CA and Williams RBG, (2009) Artificial beach recharge: the south east England experience. Zeitschrift fur Geomorphology, 52, Suppl. 3, 107-124.

Nielsen P, (2002). Shear stress and sediment transport calculations for swash zone modelling, Coastal Engineering, 45, 53-60.

Obhrai C, Powell KA and Bradbury A, (2008) A laboratory study of overtopping and breaching of shingle barrier beaches. Proceedings $31^{\text {st }}$ International Conference on Coastal Engineering, ASCE, 1497-1508.

Pedrozo-Acuña A, Simmonds DJ, Chadwick AJ and Silva R, (2007) A numerical-empirical approach for evaluating morphodynamic processes on gravel and mixed sand-gravel beaches. Marine Geology, 241, 118.

Pedrozo-Acuña A, Simmonds DJ, Otta AK and Chadwick AJ, (2006) On the cross-shore profile change of gravel beaches. Coastal Engineering, 53, 335-347.

Poate TG, Masselink G, Davidson M, McCall RT, Russell PE and Turner IL, (2013) High frequency in-situ field measurements of morphological response on a fine gravel beach during energetic wave conditions. Marine Geology, 342, 1-13. 
Poate T, Masselink G, McCall R, Almeida L, Russell PE and Davidson M, in preparation. A new wave runup equation for sand, gravel and mixed sand-gravel beaches.

Polidoro A, Dornbusch U, Pullen T, (2013) Improved maximum run-up formula for mixed beaches based on field data. In: Allsop, W. and Burgess, K. (editors), Proceedings ICE Breakwaters Conference.

Powell KA, (1990) Predicting Short Term Profile Response for Shingle Beaches. Report SR 219 HR Wallingford.

Pye K and Blott SJ, (2006) Coastal processes and morphological change in the Dunwich - Sizewell area, Suffolk, UK. Journal of Coastal Research, 22, 453-473.

Pye K and Blott SJ, (2009) Progressive breakdown of gravel-dominated coastal barrier, Dunwich-

Walberswick, Suffolk, U.K.: processes and implications. Journal of Coastal Research, 25, 589-602.

Roelvink JA, Reniers A, van Dongeren AJHM, van Thiel de Vries JSM, McCall RT and Lescinski J, (2009) Modeling storm impacts on beaches, dunes and barrier islands. Coastal Engineering, 56, 1133-1152.

She KM, Horn DP, Trim L and Canning P, (2007) Effects of permeability on the performance of mixed sand-gravel beaches. In: Kraus NC and Rosati JD (editors), Proceedings of the International Conference on Coastal Sediments, ASCE, 520-530.

Simm J D (Editor), (1991) Manual on the use of rock in coastal and shoreline engineering. CIRIA special publication 83, CUR Report 154.

Smagorinsky J, (1963) General circulation experiments with the primitive equations. Monthly Weather Review, 91, 99-164.

Smit P, Stelling G, Roelvink JA, Van Thiel de Vries J, McCall RT, Van Dongeren A, Zwinkels C and Jacobs R, (2010) XBeach: Non-hydrostatic model: Validation, verification and model description. Tech. rep., Delft University of Technology.

Smit P, Zijlema M and Stelling G, (2013) Depth-induced wave breaking in a non-hydrostatic, near-shore wave model. Coastal Engineering, 76, 1-16.

Stéphan P, Suanez S and Fichault B, (2010) Franchissement et migration des cordons de galets par rollover. Impact de la tempête du 10 mars 2008 dans l'évolution récente du Sillon de Talbert (Côtes-d'Armor, Bretagne). Norois, 215, 52-58.

Stéphan P, Suanez S and Fichaut B, (2012) Long-term morphodynamic evolution of the Sillon de Talbert gravel barrier (Brittany, France). Shore \& Beach, 80 (n 1), 19-36.

Turner IL and Masselink G, (1998) Swash infiltration-exfiltration and sediment transport. Journal of Geophysical Research, 103, 30,813-30,824.

Williams J, de Alegria-Arzaburu AR, McCall R T, van Dongeren, A, (2012) Modelling gravel barrier profile response to combined waves and tides using XBeach: Laboratory and field results. Coastal Engineering, 63, 62-80.

Zijlema M, Stelling G. and Smit P, (2011) Swash: An operational public domain code for simulating wave fields and rapidly varied flows in coastal waters. Coastal Engineering, 58, 992-1012. 